\title{
Midlatitude and high-latitude electron density profiles in the ionosphere of Saturn obtained by Cassini radio occultation observations
}

\author{
A. J. Kliore, ${ }^{1}$ A. F. Nagy, ${ }^{2}$ E. A. Marouf, ${ }^{3}$ A. Anabtawi, ${ }^{1}$ E. Barbinis, ${ }^{1}$ D. U. Fleischman, ${ }^{1}$ \\ and D. S. Kahan ${ }^{1}$ \\ Received 6 November 2008; revised 12 December 2008; accepted 30 December 2008; published 23 April 2009. \\ [1] Nineteen new radio occultations of the ionosphere of Saturn have been obtained since \\ 2006. Sixteen of these occultations were from midlatitude and high latitudes and thus \\ provided important, new information of the ionosphere for these regions. A high degree of \\ variability in the electron densities were observed, but grouping and averaging the \\ observations as low-, middle-, and high-latitude ones clearly showed that the electron \\ densities increase with latitude. The topside scale heights also indicate small increases \\ with latitude, but these changes are small enough so these increases may not be \\ statistically significant.
}

Citation: Kliore, A. J., A. F. Nagy, E. A. Marouf, A. Anabtawi, E. Barbinis, D. U. Fleischman, and D. S. Kahan (2009), Midlatitude and high-latitude electron density profiles in the ionosphere of Saturn obtained by Cassini radio occultation observations, J. Geophys. Res., 114, A04315, doi:10.1029/2008JA013900.

\section{Introduction}

[2] The Cassini spacecraft was placed in orbit around Saturn on 1 July 2004. The first set of radio occultations occurred between May and September 2005 when it was in a low-inclination orbit, and 12 observations at low latitudes were made during this period. The electron density profiles resulting from these successful occultations were published by Nagy et al. [2006] (hereinafter referred to as AFNetal), along with a relatively detailed description of the data acquisition and reduction approach. In this paper we present results which were obtained since AFNetal, as Cassini slowly moved to higher-inclination orbits during the last couple of years. Here we will only present the reduced electron density information, and will not repeat the description of the data acquisition and analysis approach, because it was identical to those already discussed for the low-latitude results of AFNetal.

\section{Results}

[3] All of the new occultations, the results of which are presented and discussed in this paper, are listed in Table 1, along with the relevant parameters. The altitudes used in this paper and in Table 1 are kronographic, that is, measured in the direction of the local vertical. So, the kronocentric altitude $\mathrm{z}_{\mathrm{kc}}$ is $\mathrm{r}-\mathrm{z}_{0}$, and the kronographic altitude is $\mathrm{z}_{\mathrm{kg}}=$

\footnotetext{
${ }^{1}$ Jet Propulsion Laboratory, California Institute of Technology, Pasadena, California, USA.

${ }^{2}$ Space Physics Research Laboratory, University of Michigan, Ann Arbor, Michigan, USA.

${ }^{3}$ Department of Electrical Engineering, San Jose State University, San Jose, California, USA.

Copyright 2009 by the American Geophysical Union. 0148-0227/09/2008JA013900
}

$\mathrm{Z}_{\mathrm{kc}} \cos \psi$, where $\psi$ is the angle between the antiradial direction and the local gravity. direction. Table 1 also lists the magnetic field $\mathrm{L}$ shell values associated with each observation (near the main peak). None of them are near the orbit of a satellite, but several connect with the rings (see Table 1).

[4] All of the Cassini electron density profiles (including those discussed by Nagy et al. [2006]) are shown together in Figure 1. Figure 1 clearly indicates major differences among the observed profiles. In order to attempt to elucidate what the data are telling us we sorted the observations by their latitudes. Because latitude changes with height during an occultation, the latitude (kronographic) at the height of the electron density peak was chosen (the range of latitudes probed by each occultation is also listed in Table 1). We also grouped the dawn and dusk low-latitude ( $\mid$ lat $\mid<20^{\circ}$ ) and midlatitude $\left(20^{\circ}<\mid\right.$ lat $\left.\mid<60^{\circ}\right)$ profiles but did not do that for the high latitudes ( $\mid$ lat $\mid>60^{\circ}$ ) because dawn and dusk lose their meaning at the near-polar latitudes.

[5] From Figure 1 it is obvious that not all profiles in each latitude range fit in uniformly with their cohort. For instance, several of the near-equatorial profiles "encroach" on the midlatitude area, and two of the midlatitude profiles look very much like those in the high-latitude group.

[6] We combined the four new low-latitude results with the previously published ones from AFNetal in order to see if any new and/or different characteristics can be observed. These dawn and dusk averages are presented in Figure 2. They are nearly identical to the previously published results, and thus the conclusion regarding the low-latitude electron densities presented by AFNetal stillstand.

[7] Next we looked at the seven midlatitude profiles; the lowest latitude in this group is $27.7^{\circ}$ and the highest is $43.6^{\circ}$. In Figure 3 we show the average of all the midlatitude observations as well as the dawn and dusk averages. 
Table 1. Parameters of New Cassini Saturn Ionospheric Occultation Results

\begin{tabular}{|c|c|c|c|c|c|c|c|c|c|}
\hline Obs. & $\begin{array}{c}\text { Peak } \\
\text { Altitude } \\
(\mathrm{km})\end{array}$ & $\begin{array}{c}1 \text { bar } \\
\text { Level } \\
(\mathrm{km})\end{array}$ & $\begin{array}{c}\text { Peak } \\
\text { Density } \\
\left(\mathrm{cm}^{-3}\right)\end{array}$ & $\begin{array}{l}\text { SZA } \\
(\mathrm{deg})\end{array}$ & $\begin{array}{l}\text { Latitude } \\
\text { (deg) }\end{array}$ & $\begin{array}{l}\text { Latitude } \\
\text { Range } \\
\text { (deg) }\end{array}$ & $\begin{array}{c}\mathrm{L} \\
\text { Shell } \\
\mathrm{R}_{\mathrm{S}} \\
\end{array}$ & Ring & $\begin{array}{l}\text { SHA } \\
\text { (h) }\end{array}$ \\
\hline $028 n$ & $1,354.7$ & $60,233.9$ & $7,463.2$ & 93.0 & -5.0 & $2.8 \mathrm{~S}$ to $5.0 \mathrm{~S}$ & 1.0 & & 18.3 \\
\hline $044 n$ & $2,000.0$ & $54,927.4$ & $35,890.3$ & 86.5 & 75.4 & $72.0 \mathrm{~N}$ to $75.4 \mathrm{~N}$ & 16.5 & & 13.6 \\
\hline $044 x$ & 700.9 & $60,240.7$ & $1,303.0$ & 95.5 & 4.5 & $0.8 \mathrm{~N}$ to $4.5 \mathrm{~N}$ & 1.0 & & 5.7 \\
\hline $046 n$ & $2,272.2$ & $60,233.4$ & $13,070.5$ & 85.2 & -5.0 & $3.5 \mathrm{~S}$ to $5.0 \mathrm{~S}$ & 1.0 & & 17.7 \\
\hline $047 \mathrm{x}$ & $2,632.3$ & $58,074.5$ & $15,220.3$ & 94.4 & -41.2 & $36.7 \mathrm{~S}$ to $41.2 \mathrm{~S}$ & 1.8 & B & 5.0 \\
\hline $051 \mathrm{n}$ & 813.8 & $58,310.3$ & $22,882.2$ & 92.4 & -38.7 & $32.3 \mathrm{~S}$ to $38.7 \mathrm{~S}$ & 1.7 & B & 18.6 \\
\hline $051 x$ & $2,820.2$ & $57,826.7$ & $10,736.4$ & 85.0 & -43.6 & $39.2 \mathrm{~S}$ to $43.6 \mathrm{~S}$ & 2.0 & B & 5.9 \\
\hline $054 n$ & $1,371.4$ & $59,834.7$ & $13,881.1$ & 94.3 & -17.9 & $15.7 \mathrm{~S}$ to $17.9 \mathrm{~S}$ & 1.1 & & 18.5 \\
\hline $054 \mathrm{x}$ & $2,382.4$ & $55,314.4$ & $21,406.8$ & 85.5 & -68.7 & $59.8 \mathrm{~S}$ to $68.7 \mathrm{~S}$ & 8.0 & & 5.3 \\
\hline $056 x$ & $2,176.8$ & $55,068.3$ & $19,720.7$ & 89.6 & -71.8 & $82.8 \mathrm{~S}$ to $71.8 \mathrm{~S}$ & 10.8 & & 19.4 \\
\hline $058 \mathrm{x}$ & $1,841.7$ & $54,914.6$ & $27,977.2$ & 89.9 & -74.1 & $81.8 \mathrm{~S}$ to $74.1 \mathrm{~S}$ & 13.9 & & 19.7 \\
\hline $068 n$ & $1,538.3$ & $59,212.9$ & $18,907.7$ & 83.8 & 27.7 & $33.2 \mathrm{~N}$ to $27.7 \mathrm{~N}$ & 1.3 & $\mathrm{C}$ & 17.3 \\
\hline $068 \mathrm{x}$ & $1,329.3$ & $55,613.5$ & $34,675.1$ & 90.0 & -65.6 & $73.6 \mathrm{~S}$ to $65.6 \mathrm{~S}$ & 6.0 & & 18.8 \\
\hline 070n & 957.6 & $57,958.0$ & $21,323.8$ & 83.9 & 42.3 & $45.8 \mathrm{~N}$ to $42.3 \mathrm{~N}$ & 1.9 & B & 17.2 \\
\hline $070 \mathrm{x}$ & $2,245.5$ & $55,283.2$ & $12,131.8$ & 90.4 & -69.1 & $75.3 \mathrm{~S}$ to $69.1 \mathrm{~S}$ & 8.2 & & 19.0 \\
\hline $072 n$ & $1,670.3$ & $58,135.8$ & $5,392.4$ & 84.3 & 40.5 & $47.2 \mathrm{~N}$ to $40.5 \mathrm{~N}$ & 1.8 & B & 17.2 \\
\hline $072 \mathrm{x}$ & 946.1 & $55,541.3$ & $35,103.2$ & 90.0 & 66.1 & $74.1 \mathrm{~S}$ to $66.1 \mathrm{~S}$ & 6.2 & & 18.8 \\
\hline $075 n$ & $1,124.1$ & $58,671.6$ & $13,463.4$ & 85.2 & 34.2 & $43.5 \mathrm{~N}$ to $34.2 \mathrm{~N}$ & 1.5 & $\mathrm{C}$ & 17.4 \\
\hline $075 x$ & 1354.4 & $55,945.4$ & 24100.2 & 89.5 & -61.8 & $68.2 \mathrm{~S}$ to $61.8 \mathrm{~S}$ & 4.6 & & 18.6 \\
\hline
\end{tabular}

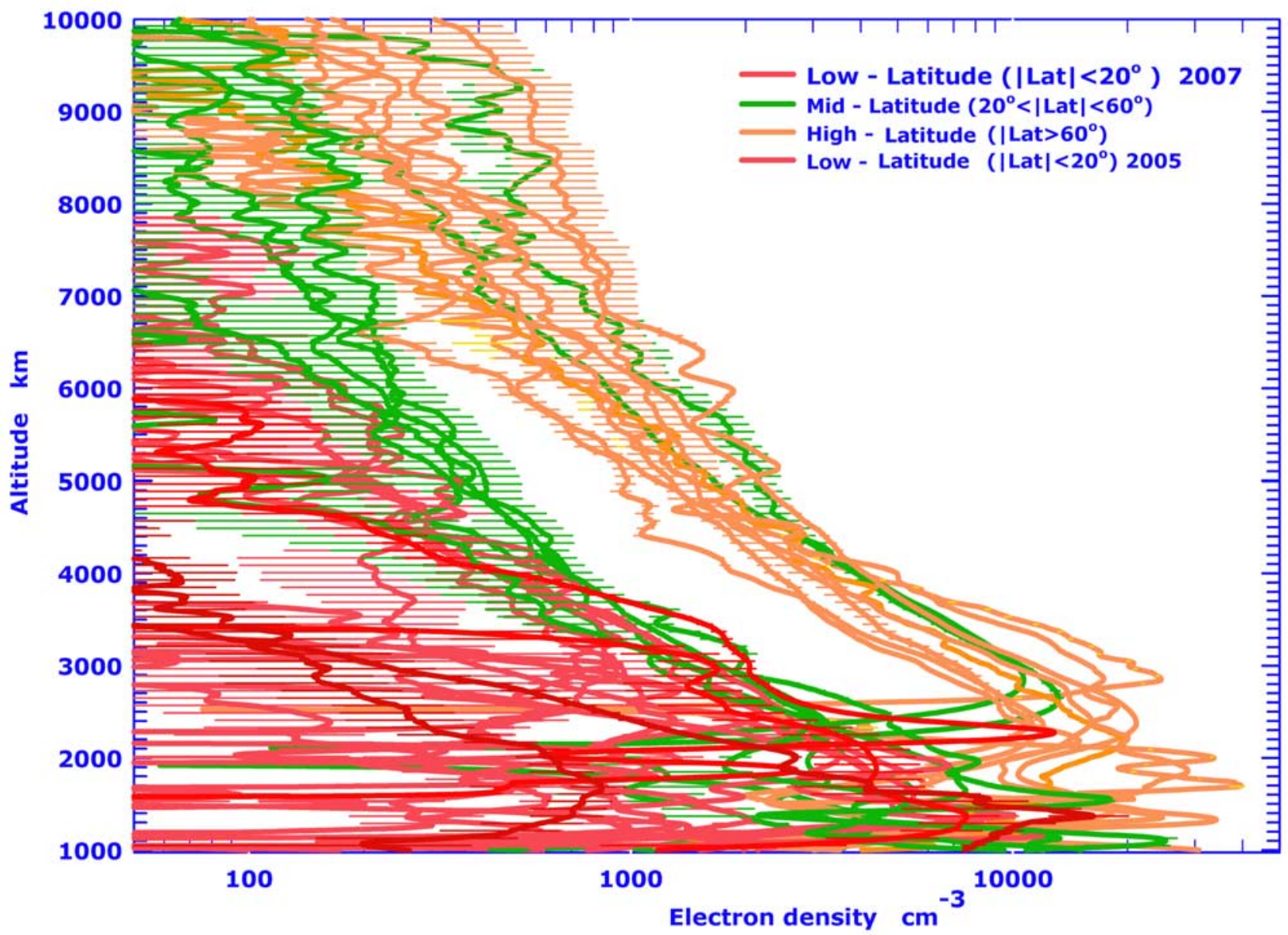

Figure 1. Electron density profiles from all Cassini occultations. 


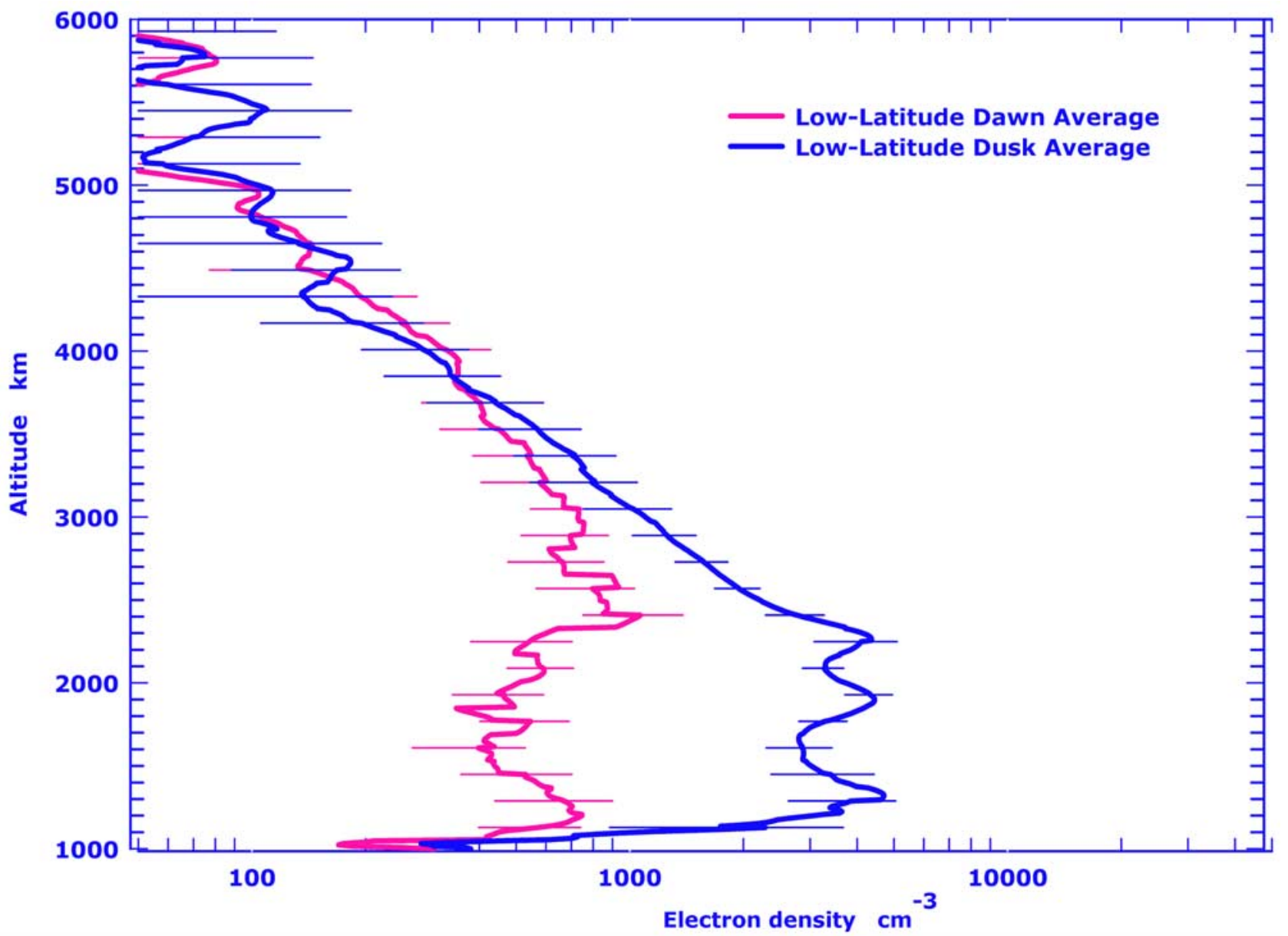

Figure 2. Low-latitude dawn and dusk averages.

However, it is important to note that the dawn average is based on only two and the dusk on five profiles, and thus they are probably not statistically reliable.

[8] We also averaged the results of the eight high-latitude profiles, which range between absolute latitudes of $61.8^{\circ}$ to $75.4^{\circ}$. We made no attempt to try to classify and separate the different high-altitude orbits as dawn or dusk. These high-latitude averages are shown in Figure 4. In order to facilitate a comparison of the high-latitude average density profiles to the low- and midlatitude ones, they are presented together in Figure 5.

[9] Finally, we show in Figure 6 the results from a single midlatitude orbit (S47 exit), which shows a sharp bite out in the density around $2000 \mathrm{~km}$. Such bite outs are not unique to this orbit, but it is rare, with only one other severe bite out seen in all the orbits so far obtained by Cassini (S44 entry, clearly apparent in Figure 4). There appears to be no systematic way to link the appearance of such bite outs to any geometrical parameter, such as latitude.

\section{Discussion}

[10] Our current understanding of Saturn's ionosphere [cf. Nagy et al., 2009] is based on electron density profiles obtained by radio occultations from Pioneer [Kliore et al., 1980], Voyager [Lindal et al., 1985], and the early phase of the Cassini mission (AFNetal). Time variations in the peak electron densities have been estimated from Saturn electrostatic discharges (SEDs), as well as a number of ionospheric models [Majeed and McConnell, 1996; Moses and Bass, 2000; Moore et al., 2006; D. E. Shemansky and X. Liu, Vertical atmospheric structure of Saturn from Cassini UVIS occultations, submitted to Icarus, 2009]. The models have been generally successful in reproducing the basic electron density altitude profile, but completely unsuccessful in being able to obtain the large, about 2 orders of magnitude, diurnal variation indicated by the SED observations. In order to achieve reasonable fits to electron density profiles, the models invoked either the presence of a significant vibrationally excited molecular hydrogen population, and/ or an influx of water. The ion composition predicted by these models generally indicate that $\mathrm{H}_{3}^{+}$is the likely main ion at lower altitude, with $\mathrm{H}^{+}$becoming dominant at the higher altitude. There are no observations to confirm these predictions; the dawn to dusk variations observed in the low-latitude profiles presented by AFNetal are "not inconsistent" with these predictions.

[11] The low-latitude electron density data, shown in Figure 2, is, as mentioned in section 1, basically the same as that presented by AFNetal. The discussions and conclusions presented in that paper are thus still appropriate and will not be discussed any further here. The new midlatitude results, shown in Figure 3, are somewhat puzzling; the average dawn densities are higher than the dusk values, 


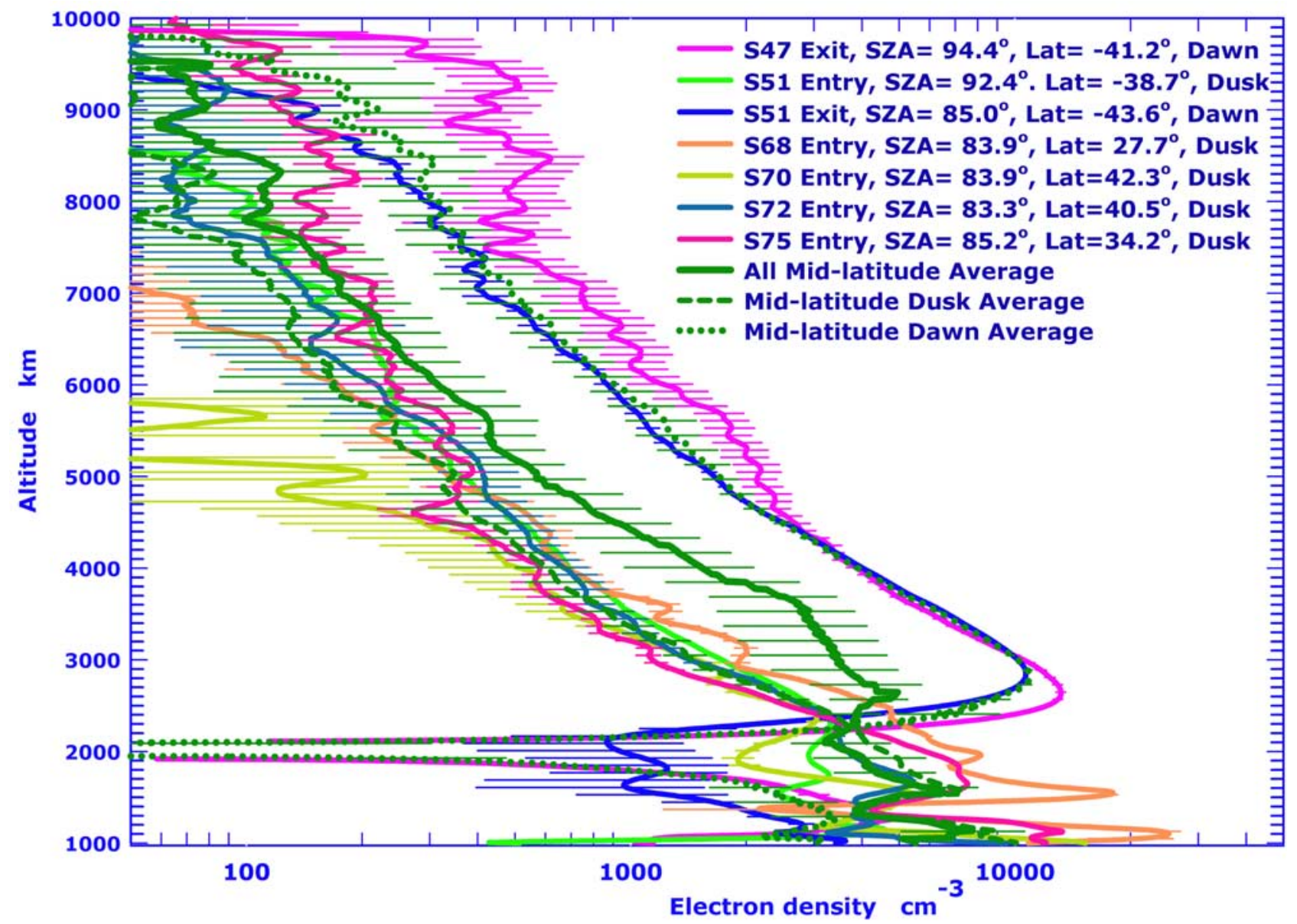

Figure 3. Cassini midlatitude observations with dawn and dusk averages.

which cannot easily be accounted for. This behavior is either due to the limited number of observations (only two dawn profiles) used in these averages and/or the result of nighttime impact ionization by some unspecified particle flux. The topside scale height of the combined midlatitude electron density is approximately $1520 \mathrm{~km}$. The dusk scale height is somewhat higher than the dawn one, but again given the poor statistics this difference is not considered/ discussed at this time. When more data become available, from later in the mission, this issue will be revisited. Assuming that $\mathrm{H}^{+}$is the main ion at these altitudes this scale height leads to a plasma temperature of about $660^{\circ} \mathrm{K}$ (this value takes into account the variation of gravity with altitude, but neglects any temperature gradients and effects due to oblateness). The scale height from high-latitude average is approximately $1610 \mathrm{~km}$; here again assuming that $\mathrm{H}^{+}$is the dominant ion the corresponding plasma temperature is about $680^{\circ} \mathrm{K}$. These plasma temperatures are somewhat higher than the model results of Moore et al. [2008], but significantly lower than what was predicted by Glocer et al. [2007] for the polar regions. The midlatitude and high-latitude plasma temperature values deduced from the data presented in this paper are also slightly higher than the low-latitude dawn value of $625^{\circ} \mathrm{K}$ obtained by AFNetal (estimation of the dusk temperature value was complicated by assumptions associated with ion composition), suggest- ing the possible presence of some nonsolar heating at higher latitudes; however, the large uncertainties associated with ion composition, temperature gradients and general observed variability means that these small differences may not be significant at all. The potential presence of energetic plasma precipitation at the mid and high-latitudes regions is consistent with the general, statistically significant, increase in the electron densities with latitude. It should be noted that we are not talking about "classical" auroral precipitation, because the majority of the observations presented here are associated with latitudes below the auroral zone.

[12] The averaged electron density profiles, shown in Figure 5 , clearly indicate that the densities increase with latitude. These increases may be the result of a number of factors/processes. Particle precipitation was already mentioned above as a possible heat source, but it can also be a source of plasma, thus enhancing electron densities. The evaluation of the realism of this potential mechanism requires quantitative future calculations, and simultaneous comparison with optical data, which are needed to set bounds on precipitation. At midlatitudes and high latitudes the potential steady source of water from the rings is reduced or eliminated. This effect results in an increase in the electron densities, but here again, much more detailed and quantitative future calculations are needed to establish 


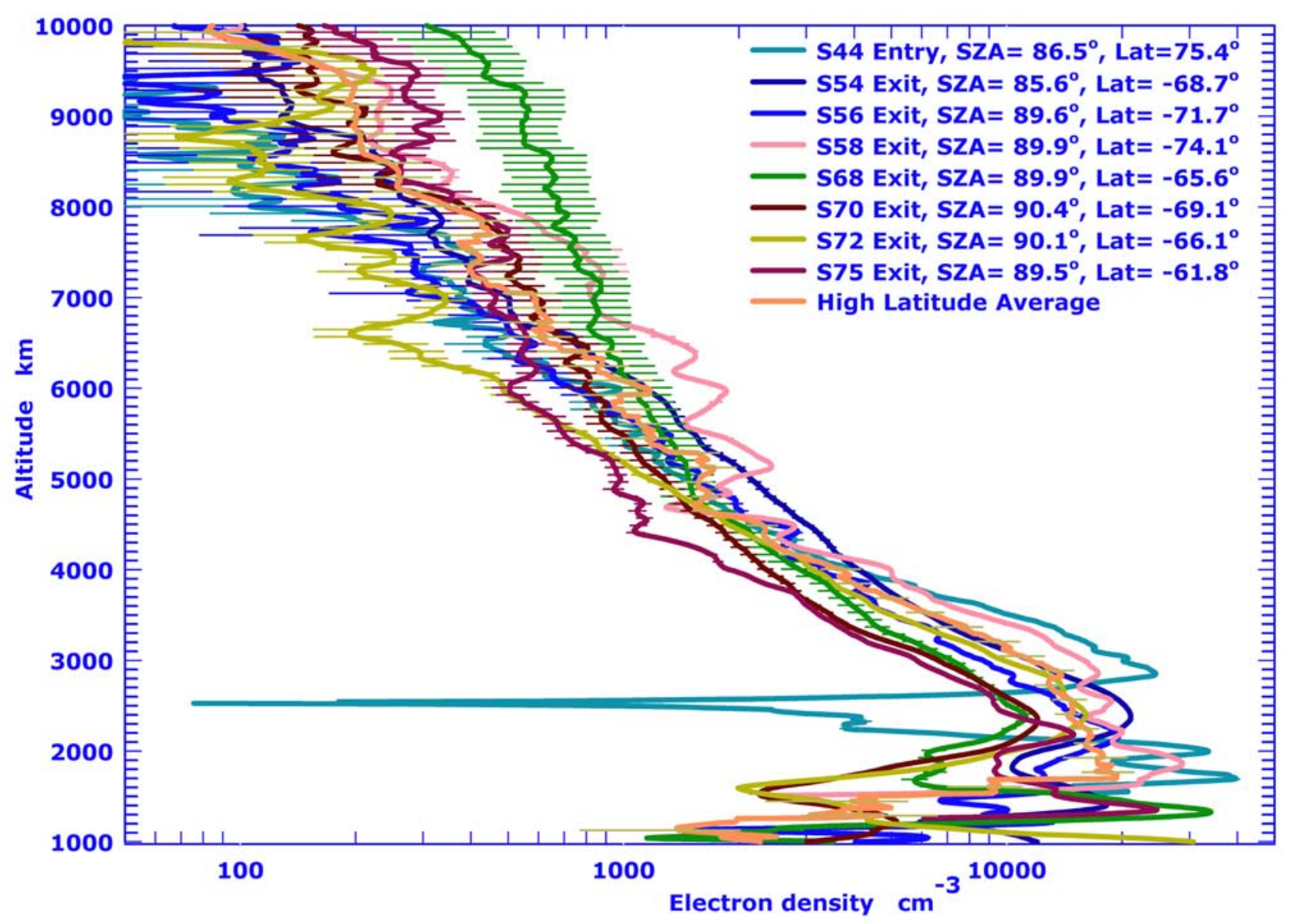

Figure 4. Cassini high-latitude ionospheric observations. 


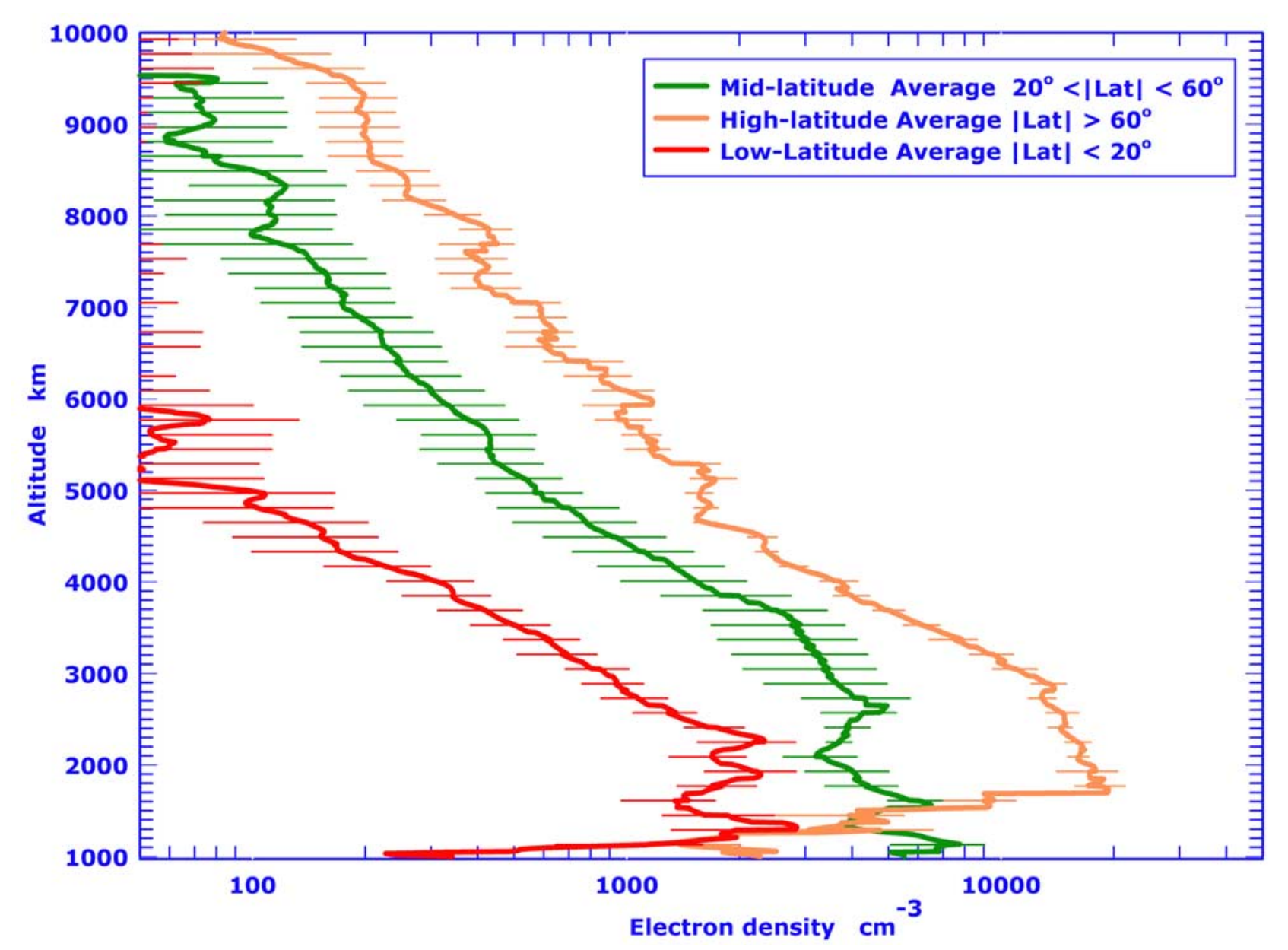

Figure 5. Averages of low-latitude, midlatitude, and high-latitude ionosphere electron density profiles. 


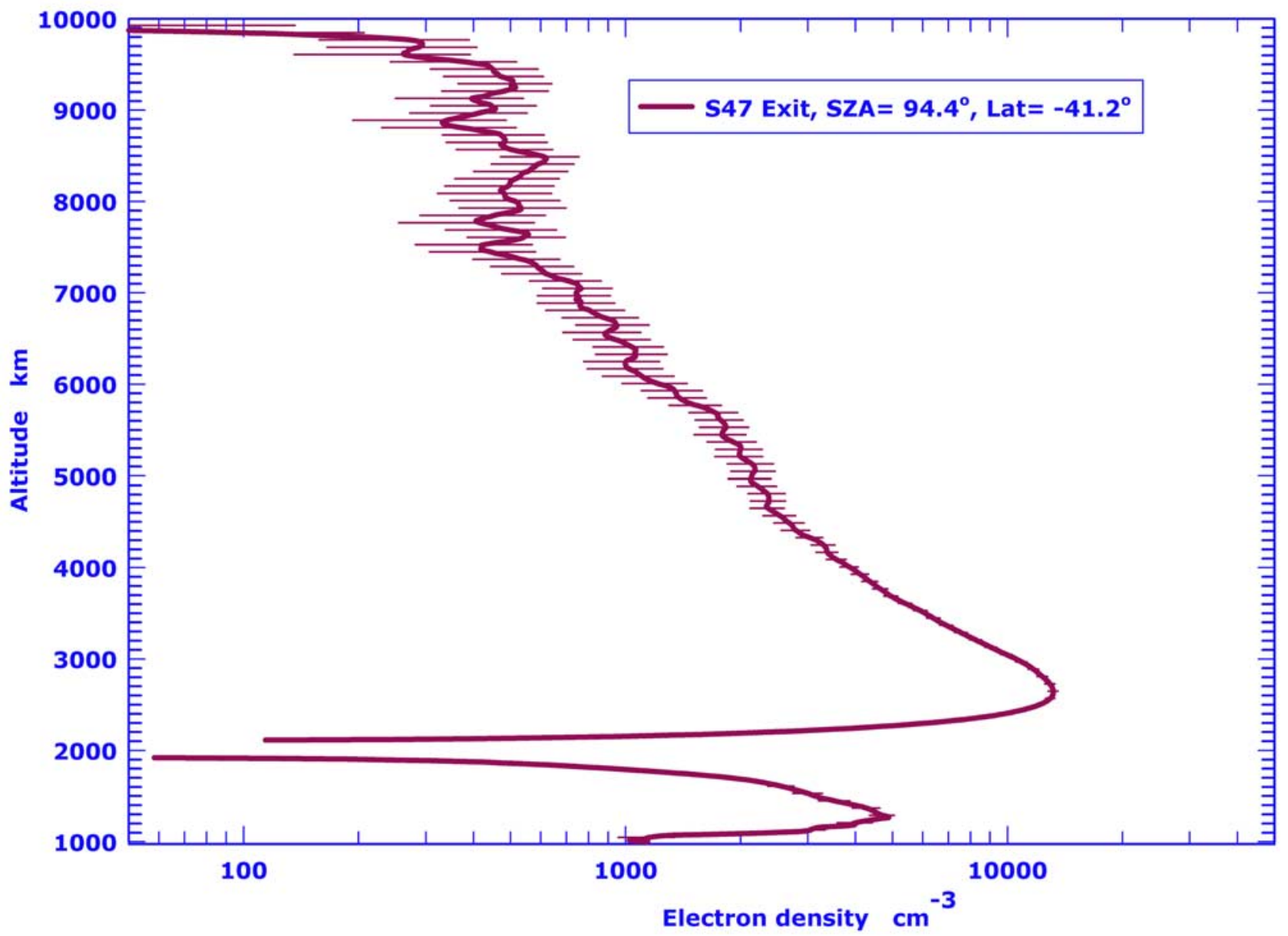

Figure 6. Unusual electron density profile from Cassini orbit 47 exit data.

whether this suggestion can explain all or part of the observed changes.

[13] Finally, a comment concerning the nature of the electron density profile shown in Figure 6 is appropriate. Moore and Mendillo [2007] have shown that a large temporary water influx into the upper atmosphere will result in a bite out similar to the observed one. However, such a large water influx (their particular simulation used an augmentation of the background water flux $\left(5 \times 10^{6} \mathrm{~cm}^{-2} \mathrm{~s}^{-1}\right)$ by a factor of 50 , which persisted for $\sim 27 \mathrm{~min}$ ) has not yet been observed, so one cannot draw definitive conclusion at this time. On the other hand, there were only two such large bite outs observed among the 19 occultations presented here, so one needs such large fluxes only "intermittently."

[14] Matcheva et al. [2001] examined the potential role of gravity waves as the mechanism responsible for large and sharp electron density peaks observed by Galileo at Jupiter. They point out that at higher altitudes where long-lived $\mathrm{H}^{+}$ dominates diffusion is likely to dominate and act to limit large deviations from diffusive equilibrium. They showed that at Jupiter, in the altitude range of between about 600 and $900 \mathrm{~km}$, gravity waves are likely to be important in creating the observed sharp, multiple density peaks. At this point without a careful quantitative calculation it is impossible to come to a definitive conclusion regarding the observed bite out at Saturn. As indicated in Figure 6, the very large bite out is at $2000 \mathrm{~km}$ where the $\mathrm{H}^{+}$density is likely to be comparable or even exceed the $\mathrm{H}_{3}^{+}$density and the diffusion lifetimes are significant compared to the rotation period of the planet, thus such large perturbation may not be caused by gravity waves; on the other hand the smaller bite out seen around $1000 \mathrm{~km}$ could certainly be caused by the mechanism proposed by Matcheva et al. [2001].

[15] In summary, the new electron density result presented in this paper, indicate significant orbit to orbit variabilities, but the average low-, middle-, and highlatitude profiles indicate that the electron densities increase with latitude. The topside scale heights also indicate small increases with latitude, but they may not be statistically significant.

[16] Acknowledgments. The authors wish to express their gratitude to the Cassini Project, the personnel of the NASA/JPL Deep Space Net, an the JPL Radio Science Systems group for the highly successful acquisition of the Radio Science Data. We are also indebted to M. Mendillo and D. Strobel for their thoughtful and comprehensive reviews that significantly improved this paper. This work was performed at the Jet Propulsion Laboratory, California Institute of Technology, and at the University of Michigan under NASA contracts.

[17] Wolfgang Baumjohann thanks Darrell Strobel and another reviewer for their assistance in evaluating this paper 


\section{References}

Glocer, A., T. I. Gombosi, G. Toth, K. C. Hansen, A. J. Ridley, and A. Nagy (2007), Polar wind outflow model: Saturn results, J. Geophys. Res., 112, A01304, doi:10.1029/2006JA011755.

Kliore, A. J., et al. (1980), Structure of the ionosphere and atmosphere of Saturn from Pioneer 11 Saturn radio occultation, J. Geophys. Res., 85, 5857-5870, doi:10.1029/JA085iA11p05857.

Lindal, G. F., D. N. Sweetnam, and V. R. Eshleman (1985), The atmosphere of Saturn: An analysis of the Voyager radio occultation measurements, Astron. J., 90, 1136-1146, doi:10.1086/113820.

Majeed, T., and J. C. McConnell (1996), Voyager electron density measurements on Saturn: Analysis with a time dependent ionospheric model J. Geophys. Res., 101, 7589-7598, doi:10.1029/96JE00115.

Matcheva, K. I., D. F. Strobel, and F. M. Flasar (2001), Interaction of gravity waves with ionospheric plasma: Implications for Jupiter's ionosphere, Icarus, 152, 347-365, doi:10.1006/icar.2001.6631.

Moore, L., and M. Mendillo (2007), Are plasma depletions in Saturn's ionosphere a signature of time-dependent water input?, Geophys. Res. Lett., 34, L12202, doi:10.1029/2007GL029381.

Moore, L., A. F. Nagy, A. J. Kliore, I. Müller-Wodarg, J. D. Richardson, and M. Mendillo (2006), Cassini radio occultations of Saturn's ionosphere: Model comparisons using a constant water flux, Geophys. Res. Lett., 33, L22202, doi:10.1029/2006GL027375.
Moore, L., M. Galand, I. Mueller-Wodarg, R. Yelle, and M. Mendillo (2008), Plasma temperatures in Saturn's ionosphere, J. Geophys. Res. 113, A10306, doi:10.1029/2008JA013373.

Moses, J. I., and S. F. Bass (2000), The effects of external material on the chemistry and structure of Saturn's ionosphere, J. Geophys. Res., 105, 7013-7052, doi:10.1029/1999JE001172.

Nagy, A. F., et al. (2006), First results from the ionospheric radio occultations of Saturn by the Cassini spacecraft, J. Geophys. Res., 111, A06310, doi:10.1029/2005JA011519.

Nagy, A. F., et al. (2009), Upper atmosphere and ionosphere of Saturn, in Saturn After Cassini-Huygens, edited by A. F. Nagy et al., Springer, New York, in press.

A. Anabtawi, E. Barbinis, D. U. Fleischman, D. S. Kahan, and A. J. Kliore, Jet Propulsion Laboratory, California Institute of Technology, MS 161-260, 4800 Oak Grove Drive, Pasadena, CA 91109, USA. (akliore@ jpl.nasa.gov)

E. A. Marouf, Department of Electrical Engineering, San Jose State University, One Washington Square, San Jose, CA 95192-0084, USA.

A. F. Nagy, Space Physics Research Laboratory, University of Michigan, 2455 Hayward Street, Suite 1422, Ann Arbor, MI 48109-2143, USA. 